\title{
Phase Speed Spectra and the Latitude of Surface Westerlies: Interannual Variability and Global Warming Trend
}

\author{
GANG CHEN \\ Program in Atmospheres, Oceans, and Climate, Massachusetts Institute of Technology, Cambridge, Massachusetts \\ JIAN LU \\ National Center for Atmospheric Research, Boulder, Colorado \\ DARGAN M. W. Frierson \\ University of Washington, Seattle, Washington
}

(Manuscript received 31 October 2007, in final form 23 April 2008)

\begin{abstract}
The extratropical annular-mode-like atmospheric responses to ENSO and global warming and the internal variability of annular modes are associated with similar, yet distinct, dynamical characteristics. In particular, La Niña, global warming, and the positive phase of annular modes are all associated with a poleward shift of midlatitude jet streams and surface westerlies. To improve understanding of these phenomena, the authors identify and compare patterns of interannual variability and global warming trends in the midlatitude surface westerlies and the space-time spectra of associated eddy momentum fluxes by analyzing simulations of the present climate in an atmosphere-only climate model, in which the ENSOinduced extratropical response is validated with that in reanalysis data, and by projection of future climate changes using a coupled atmosphere-ocean model.

While the response to ENSO is consistent with the refraction of midlatitude eddies due to subtropical wind anomalies, the interannual internal variability of the annular modes marks a change in the eastward propagation speed of midlatitude eddies. In response to global warming, the dominant eddies exhibit a trend toward faster eddy phase speeds in both hemispheres, in a manner similar to the positive phase of interannual internal variability. These diagnoses suggest that the annular mode trend due to greenhouse gas increases may be more related to extratropical processes, especially in the upper troposphere/lower stratosphere, rather than being forced from the deep tropics.
\end{abstract}

\section{Introduction}

The intraseasonal and interannual variability of extratropical circulations in both hemispheres is characterized by remarkably zonally symmetric or annular patterns. The Southern Hemisphere (SH) and Northern Hemisphere (NH) annular modes (SAM and NAM), defined by the variability of sea level pressure, are associated with changes of an equivalent barotropic structure in tropospheric zonal wind, temperature, and geopotential height (Thompson and Wallace 2000).

Corresponding author address: Gang Chen, Program in Atmospheres, Oceans, and Climate, Massachusetts Institute of Technology, Cambridge, MA 02139.

E-mail: gchenpu@mit.edu
The dipolar structure of annular modes in latitude represents the meridional vacillation of surface westerlies and upper tropospheric eddy-driven jets about their climatological mean positions. This zonal wind variability is generally attributed to the internal variability of the atmosphere that arises from eddy-mean flow interactions (e.g., Hartmann and Lo 1998; Limpasuvan and Hartmann 2000; Lorenz and Hartmann 2001, 2003). Similar zonal flow vacillations can be found in idealized models without topography, seasonal cycle, or sea surface temperature variations (e.g., Robinson 1991; James and James 1992; Yu and Hartmann 1993; Feldstein and Lee 1996; Limpasuvan and Hartmann 2000; Cash et al. 2002).

On interannual time scales, the extratropical zonal flow is also affected by the El Niño-Southern Oscilla- 
tion (ENSO). In addition to the zonally asymmetric Rossby wave teleconnection pattern (e.g., Hoskins and Karoly 1981), the extratropical circulation response to ENSO has a zonally symmetric component that projects strongly onto the SAM during austral summer (Robinson 2002; Seager et al. 2003; L'Heureux and Thompson 2006). These extratropical changes can be roughly explained by the impact of subtropical zonal wind anomalies on the equatorward propagation and absorption of midlatitude eddies near their critical latitudes, and subsequently on the eddy-driven extratropical circulation (Chang 1995, 1998; Robinson 2002; Seager et al. 2003). While this argument emphasizes the importance of quasi-linear Rossby wave propagation, other factors such as eddy intensity or zonal asymmetry can still play a role in the jet movements associated with the ENSO variability. Orlanski $(2003,2005)$ argues that, as the surface baroclinicity is increased in El Niño years, nonlinear wave breaking can undergo a transition from an anticyclonic wave breaking regime to a cyclonic regime and result in an equatorward jet shift. Abatzoglou and Magnusdottir (2006) find that the observed events of planetary wave breaking in the Northern Hemisphere are increased considerably during La Niña years, which can also influence the structure of the subtropical jet.

Additionally, observations reveal positive annular mode trends in both hemispheres in recent decades (e.g., Thompson et al. 2000; Thompson and Solomon 2002). These trends are seen in model simulations of present climate and projections for future climate change and have been attributed to greenhouse gas increases and stratospheric ozone depletion (e.g., Fyfe et al. 1999; Kushner et al. 2001; Gillett and Thompson 2003). Although stratospheric ozone loss may be a greater contributor to the observed SAM trend in the late twentieth century, greenhouse gas increases will likely sustain and continue the positive annular mode trends in both hemispheres throughout the twenty-first century against the predicted recovery of stratospheric ozone concentrations (Shindell and Schmidt 2004; Arblaster and Meehl 2006; Miller et al. 2006). These annular mode trends under global warming are associated with a poleward shift of midlatitude storm tracks (Yin 2005), a rise in the tropopause height (Lorenz and DeWeaver 2007), and an expansion of the Hadley cell (Lu et al. 2007). Despite the projected El Niño-like tropical SST pattern in most models for the Fourth Assessment Report of the Intergovernmental Panel on Climate Change (IPCC), the responses in the Hadley cell width, extratropical circulation, and hydrological cycle to global warming appear to be opposite to those associated with El Niño forcing, implicative of the im- portance of extratropical eddies in generating this poleward shift (Lu et al. 2008).

In this paper, we identify and compare changes in eddy characteristics associated with these annular patterns of interannual variability and global warming trend in the boreal winter/austral summer. We examine these annular variations with respect to the latitude of surface westerlies, which is highly correlated with the phase of annular mode. This is motivated from the perspective of angular momentum balance: in the monthly and zonal average, the surface stress, generally quadratic to surface winds, is equal to the vertical integral of momentum flux convergence minus mountain drag and gravity wave drag (e.g., Huang et al. 1999). We first show the consistency in the variations of eddy momentum flux convergence and surface winds and then attribute the surface wind variation to the unforced or forced variability in eddy momentum fluxes associated with Rossby wave propagation.

The poleward eddy momentum flux is the consequence of equatorward Rossby wave propagation. As discussed in Held (2000), Rossby waves can be thought of as being stirred by midlatitude baroclinic instability and then propagating to the subtropics. As waves approach their critical latitudes, where the phase speed of eddies equals the background zonal flow, waves grow in amplitude and break irreversibly, resulting in the absorption of wave activity. The sources and sinks of wave activity are accompanied by the acceleration and deceleration of zonal winds. This quasi-linear perspective of the atmosphere is justified by the fact that wave activity can be further decomposed into contributions from modes of various scales and phase speeds, and these modal properties are conserved as waves propagate meridionally in a zonally symmetric background flow (Held 1985). (Note that such modal orthogonality does not hold for energy or enstrophy.) To highlight this modal property with respect to the background zonal flow, Randel and Held (1991) introduced the phase speed spectrum, which decomposes eddy fluxes as a function of phase speed and wavenumber or phase speed and latitude. The phase speed spectrum shows clearly that the midlatitude eddies are mostly absorbed near their linear critical latitudes in the subtropics, the slower eddies can penetrate more deeply into the tropics, and the critical latitudes of faster eddies are farther poleward. Also, plotting the eddy spectrum as a function of latitude allows one to distinguish the changes in midlatitude wave sources versus those in subtropical wave sinks and therefore attribute the changes in the subtropical wave breaking to baroclinic growth versus barotropic decay of eddies. Here we use this spectral analysis to help understand the role of eddies in the 
aforementioned annular mode variability on various time scales.

The paper is organized as follows: We first describe the reanalysis data and climate models used in this study in section 2 . Then, we show the variability in the latitude of surface westerlies and associated eddy spectra on various time scales. We compare the ENSOinduced interannual variability between the 40-yr European Centre for Medium-Range Weather Forecasts Re-Analysis (ERA-40) and the ensemble mean of the Geophysical Fluid Dynamics Laboratory (GFDL) atmosphere-only model in section 3 . Next, we present the internal interannual variability in section 4 only for the model, in which the ensemble mean extratropical variability forced by SST and radiative forcings can be effectively removed. In section 5 , we describe the response to global warming in the GFDL coupled climate model. Finally, we provide brief conclusions and discussion in section 6 .

\section{Data and methodology}

We first study the interannual variability of the latitude of surface westerlies and the space-time spectrum of upper tropospheric eddies in ERA-40 and AM2.1. ERA-40 is the latest reanalysis product from the European Centre for Medium-Range Weather Forecasts (Uppala et al. 2005); AM2.1 is the GFDL global atmosphere and land model (Anderson et al. 2004). The model simulations consist of 10 ensemble members, forced by estimates of the observed changes in SSTs, sea ice, well-mixed greenhouse gases, tropospheric and stratospheric ozone, volcanic and anthropogenic aerosols, solar irradiance, and land use.

Both ERA-40 and AM2.1 display poleward shifts of Southern Hemisphere surface westerlies in the late twentieth century, which have been attributed, at least partially, to stratospheric ozone depletion (Chen and Held 2007). In spite of the decadal trend, the statistics of interannual variability of surface westerlies in AM2.1 are almost identical to another ensemble of experiments in which radiative forcings are fixed at 1860 conditions. Therefore, the interannual variability of annular modes can be thought of as being generated, arguably, by SST variations in the tropics and atmospheric eddy-mean flow interactions in the extratropics. We first validate the model performance by comparing the ENSO-induced extratropical responses in ERA-40 and AM2.1 and then examine the intrinsic variability of annular modes in AM2.1, after subtracting the ensemble mean model response to SST and radiative forcings.

The spatial patterns associated with the interannual ENSO variability are obtained from linear regression onto the detrended "Cold Tongue Index" (CTI) normalized by its own standard deviation. The CTI is defined as the SST anomalies averaged between $6^{\circ} \mathrm{N}$ and $6^{\circ} \mathrm{S}, 180^{\circ}$ and $90^{\circ} \mathrm{W}$ (Deser and Wallace 1990), and the regression onto the inverted CTI represents the La Niña-induced response. Similar regression is also carried out for a surface westerly latitude (SWL) index. The SWL quantifies the variability of the surface westerlies and is defined as the mean latitude of zonally averaged surface westerlies in midlatitudes weighted by the wind strength:

$$
\begin{gathered}
\mathrm{SWL}=\int_{20^{\circ}}^{70^{\circ}} \phi(\bar{u} \cos \phi) d \phi / \int_{20^{\circ}}^{70^{\circ}}(\bar{u} \cos \phi) d \phi \text { for } \\
\bar{u}>0,
\end{gathered}
$$

where $\bar{u}$ denotes the zonal-mean surface zonal wind. The time series of SWL represents the meridional movement of surface westerlies and is highly correlated with the corresponding annular mode index.

We compute the regression patterns of most fields, using 24 years of reanalysis (1979-2002) in ERA-40 and the ensemble mean of 10 realizations over 21 years (1979-99) in AM2.1. Despite improved data quality in the reanalysis after 1979, our results are rather similar when the data prior to the satellite era are included. Furthermore, AM2.1 can simulate the seasonal variation of ENSO-induced surface wind anomalies in ERA40 rather well with maximum shifts in the boreal winter and austral summer (Chen 2007), consistent with the observed extratropical upper tropospheric wind anomalies (Seager et al. 2003; L'Heureux and Thompson 2006). Therefore, we focus on the seasonal average from December to March (DJFM) in this study.

In calculating the phase speed spectrum, we first obtain the space-time spectrum (Hayashi 1971) of eddy momentum flux in each year, using the 120-day DJFM daily data tapered by a Hanning window. Following the method introduced in Randel and Held (1991), the spectrum is further transformed as a function of angular phase speed and wavenumber. Again, the anomalous pattern is obtained through linear regression of the yearly space-time spectrum. We use 44 years (19592002) in ERA-40 so as to increase the statistical significance in the spectral space. Meanwhile, 10 realizations of 40 years (1960-99) in AM2.1 are employed to compute the eddy spectrum, although the results are nearly unchanged by using only half of the record.

Additionally, we have examined global warming projections for the twenty-first century in the GFDL coupled atmosphere-ocean model, CM2.1 (Delworth et al. 2006). To highlight the greenhouse gas signal, we 

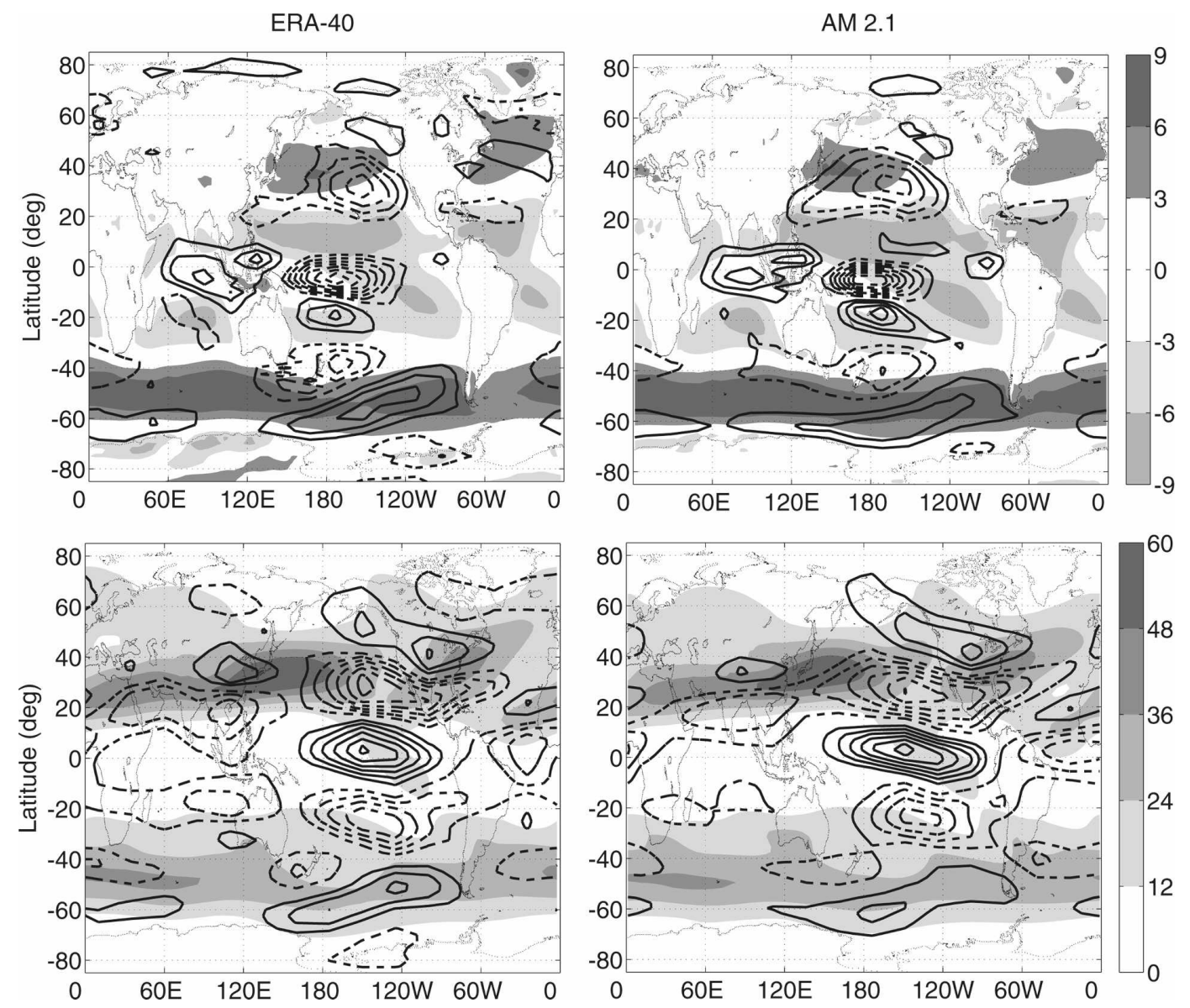

FIG. 1. Spatial pattern of the DJFM mean zonal wind anomalies at (top) the surface and (bottom) $250 \mathrm{hPa}$ regressed onto the inverted CTI for (left) ERA-40 and (right) the AM2.1 ensemble mean. Shading represents the climatological mean winds; contours represent the anomalies associated with one standard deviation of the inverted CTI: intervals are (top) $0.3 \mathrm{~m} \mathrm{~s}^{-1}$ and (bottom) $1 \mathrm{~m} \mathrm{~s}^{-1}$.

present the results from the IPCC A2 scenario, a highemission scenario with $\mathrm{CO}_{2}$ concentrations rising to 820 ppm in 2100. The global warming response is calculated as the 20-yr mean of 2081-2100 minus the 20-yr mean of 2001-20. In contrast to the ENSO response, the poleward shift of surface westerlies under global warming has a weaker seasonal dependence. The displacement of Southern Hemisphere westerlies is pronounced throughout the year, although the shift in the austral winter is accompanied by a notable strengthening of the westerlies (Chen 2007; Lorenz and DeWeaver 2007).

\section{The ENSO-induced variability}

Figure 1 shows the spatial pattern of DJFM mean zonal wind anomalies at the surface and $250 \mathrm{hPa}$ regressed onto the inverted CTI for ERA-40 and for the ensemble mean in AM2.1. As is well established in the literature, the zonal winds are characterized by anoma- lous surface easterlies and upper tropospheric westerlies over the tropical Pacific Ocean. There is a hemispherically symmetric weakening in the upper tropospheric winds over the subtropical Pacific, as expected from cooler-than-normal SST anomalies in the tropical Pacific and the thermal wind relationship. In the extratropics, the Southern Hemisphere surface westerlies displace poleward over the Pacific and Atlantic oceans, but the Northern Hemisphere westerlies are weakened on the equatorward side in the Pacific, and exhibit little change in the Atlantic. The extratropical wind change has an equivalent barotropic structure in the vertical and extends eastward in the upper levels. All these tropical and extratropical circulation responses associated with the cold phase of ENSO cycle are well simulated in the model. As is noted in Seager et al. (2003) and L'Heureux and Thompson (2006), the zonal wind change associated with the ENSO cycle exhibits a great degree of hemispheric symmetry over the Pacific Ocean 

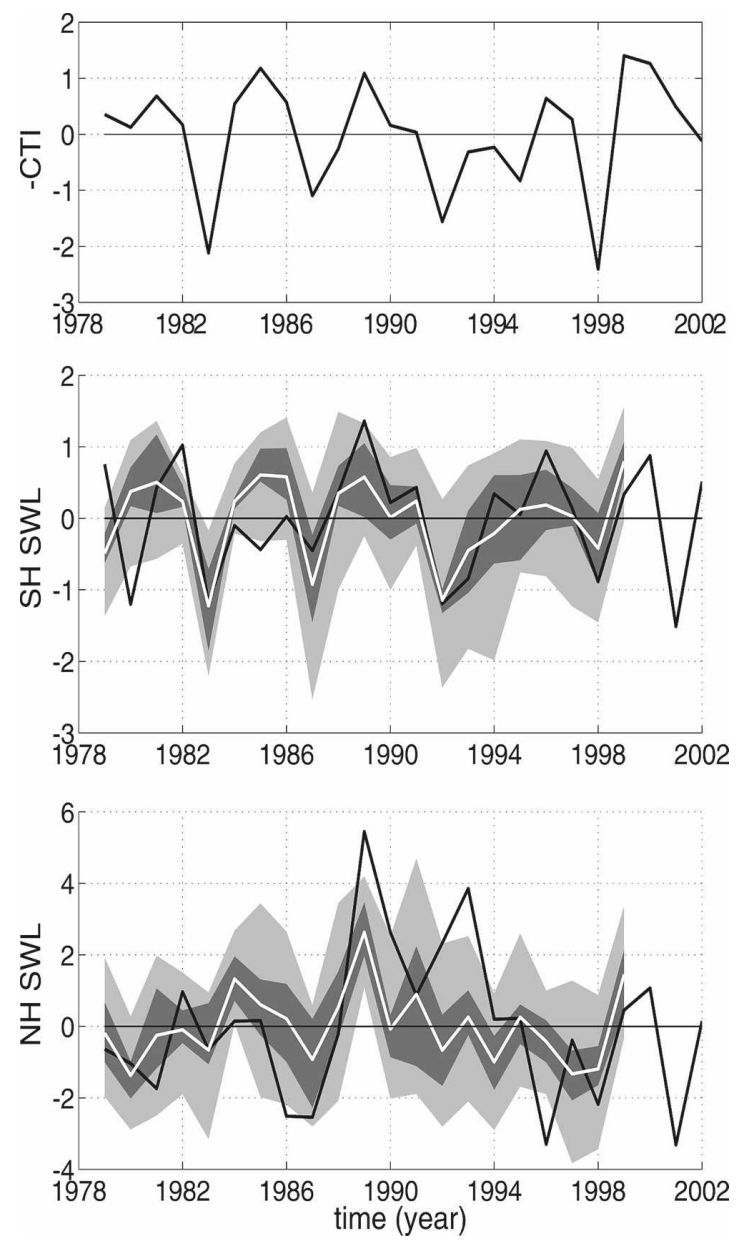

FIG. 2. The DJFM-averaged (top) detrended and standardized inverted Cold Tongue Index (CTI) and the ensemble means and spreads of the detrended SWLs in the (middle) SH and (bottom) $\mathrm{NH}$ from 1979 to 2002. Years on the axis represent the years of JFM being averaged. SWL is the surface westerly latitude defined in Eq. (1), and the positive value represents a poleward shift. The black and white lines denote the SWLs for ERA-40 and the model ensemble mean, respectively. The SWLs in each year for the ensemble experiments are ranked in an ascending order as $y_{i}$ $(i=1, \ldots, 10)$. The shading is between $\left(y_{1}+y_{2}\right) / 2$ and $\left(y_{9}+\right.$ $\left.y_{10}\right) / 2$; the dark shading is between $\left(y_{3}+y_{4}\right) / 2$ and $\left(y_{7}+y_{8}\right) / 2$.

and a notable zonally symmetric component, especially in the $\mathrm{SH}$ and in the $\mathrm{NH}$ upper troposphere.

The relationship between the detrended CTI and SWLs in the two hemispheres in DJFM is illustrated in Fig. 2 for ERA-40 and for the AM2.1 ensemble mean with the spread among 10 realizations. As is easily seen in the figure, the El Niño events are associated with an equatorward shift of SH surface westerlies, and both the reanalysis and the model show a statistically significant correlation between the CTI and the SH SWL. The correlation coefficient is 0.55 for ERA-40, and the average of correlations in AM2.1, $\Sigma r_{i} \sigma_{i} /\left(\Sigma \sigma_{i}^{2}\right)^{1 / 2}$ (where $r_{i}$ and $\sigma_{i}$ are the correlation coefficient and standard deviation of SWL for the $i$ th realization), is 0.52 , suggesting that ENSO explains about one quarter of the latitudinal variability of SH surface westerlies, consistent with the observed correlation between the CTI and the SAM in the National Centers for Environmental Prediction (NCEP)-National Center for Atmospheric Research (NCAR) reanalysis (L'Heureux and Thompson 2006). However, the NH SWL is not significantly correlated with the CTI, which is especially noticeable in the SWL time series in the reanalysis. We have separated the contributions to the correlation coefficient between the North Atlantic and North Pacific, and the North Pacific is much more correlated with CTI than the North Atlantic, as expected from the Pacific-North American (PNA) teleconnection pattern. Since the Atlantic storm tracks are at least as active as the Pacific storm tracks, one can also see this zonal asymmetry directly from Fig. 1. Keeping this zonal asymmetry in mind, we proceed to examine the zonally averaged response in the extratropical circulations.

We compare the ENSO-induced anomalies in the surface winds and upper tropospheric eddies for ERA40 and for the AM2.1 ensemble means with the spread among 10 realizations. Figure 3 shows the climatological means (dashed lines) and ENSO regression patterns (solid lines) for the DJFM and the zonally averaged (bottom) surface stress and the corresponding (top) transient and (middle) stationary eddy momentum flux convergence with a pressure-weighted average between 100 and $500 \mathrm{hPa}$. The stationary eddies are defined by the DJFM seasonal means, and transient eddies are the deviations from the seasonal means. More precisely, the stationary eddy momentum flux is defined as $\left[\bar{v}^{*} \bar{u}^{*}\right]$, and the transient eddy flux is $\overline{\left[\left(v^{\prime}\right)^{*}\left(u^{\prime}\right)^{*}\right]}$, where brackets (overbars) denote the zonal (time) means and asterisks (primes) denote the deviations from zonal (time) means. The cutoff period for transient waves here is arbitrary. Later in the paper, we will further divide transient waves into planetary-scale waves with zonal wavenumbers 1-3 and medium-scale waves with wavenumbers 4-7. The characteristics of planetaryscale transient waves resemble those of stationary waves defined here, and the behaviors of medium-scale waves are quite similar in the two hemispheres.

The model simulates a consistent response in circulation quite similar to the reanalysis. The anomalous transient eddy momentum flux displays a latitudinal fluctuation between divergence and convergence, with a great degree of hemispheric symmetry (Seager et al. 2003; L'Heureux and Thompson 2006). In the extratropics, the SH surface westerlies shift poleward, con- 
ERA-40
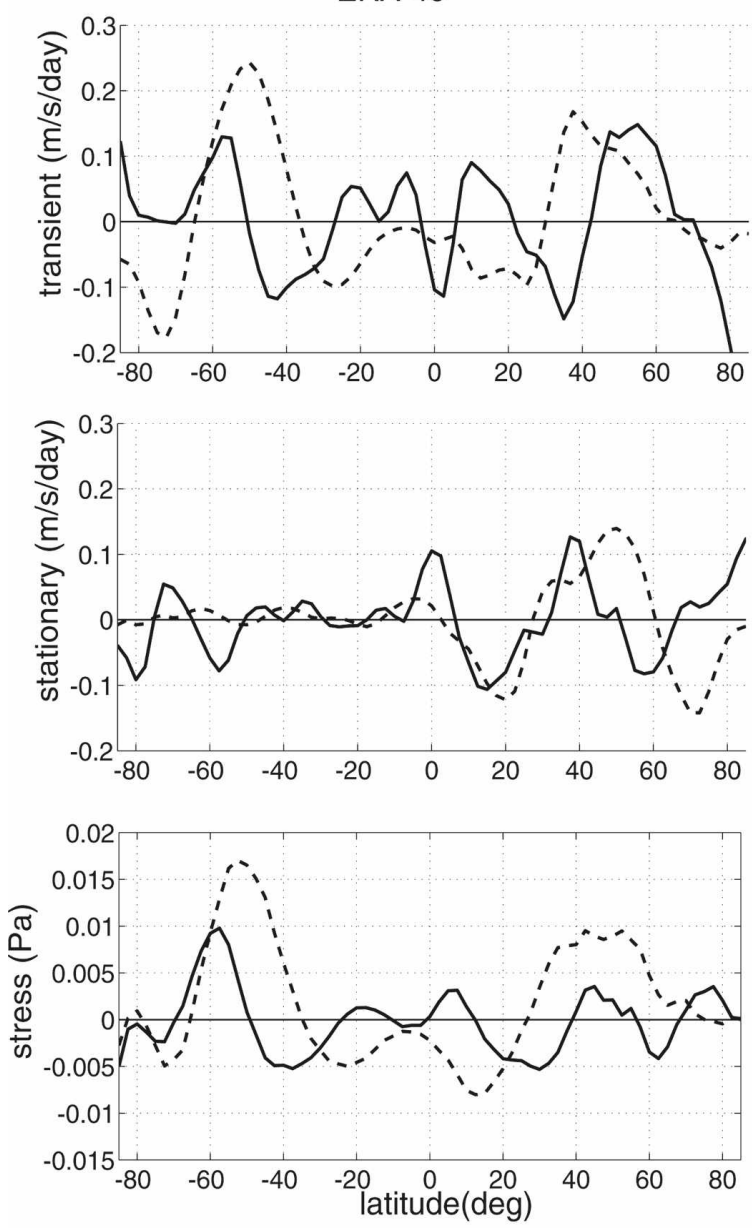

AM 2.1
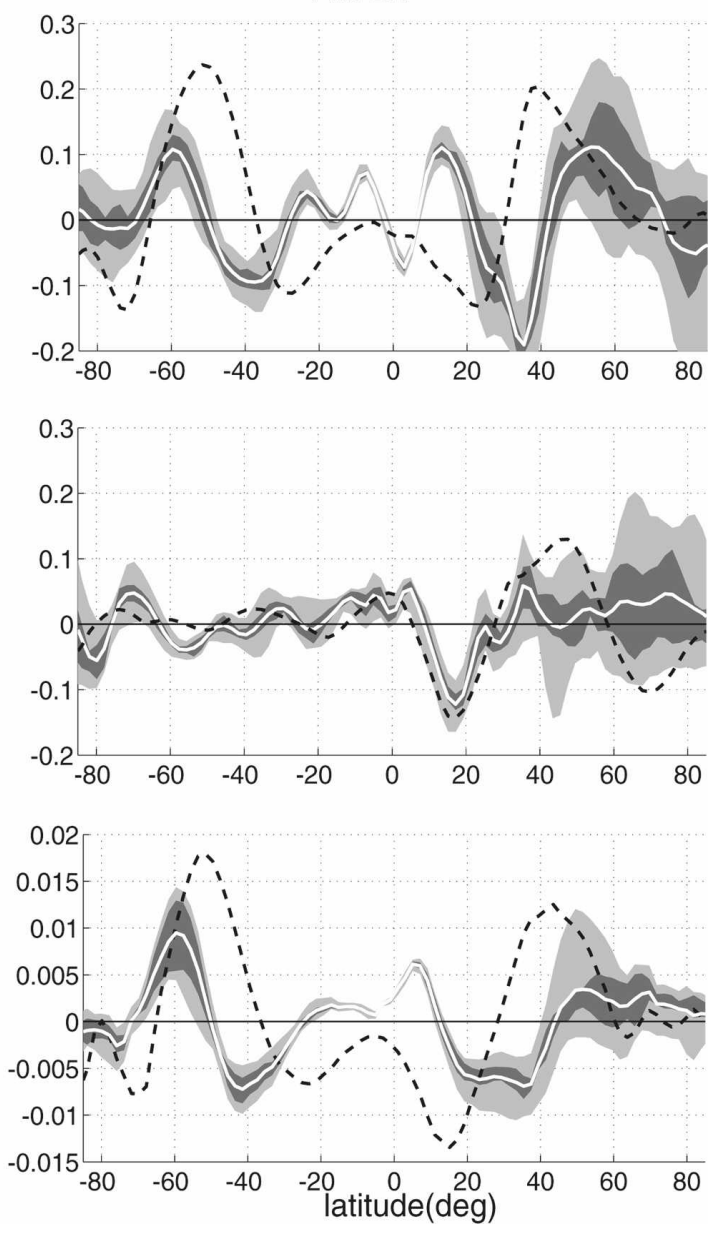

FIG. 3. ENSO-induced anomalies in the upper tropospheric eddy momentum flux convergence and surface stress for (left) ERA-40 and for (right) the AM2.1 ensemble means with the spread among 10 realizations. The black/white solid lines are the La Niña regression patterns of the DJFM and zonally averaged (bottom) surface stress and the corresponding (top) transient and (middle) stationary eddy momentum flux convergence with a pressure-weighted average between 100 and $500 \mathrm{hPa}$, and the dashed lines are $1 / 10$ of the climatological means. The model ensemble spread is ranked and plotted in gray shading as in Fig. 2.

sistent with the movement of transient eddy momentum flux convergence in the upper troposphere. The $\mathrm{NH}$ response is more complicated. The $\mathrm{NH}$ surface westerlies are clearly reduced on the equatorward side of the westerly maximum, but the ensemble mean increase on the poleward side in the model is smaller than the spread among different realizations. The transient momentum flux convergence displaces poleward, but this displacement is partially undermined by anomalous stationary eddy flux, which displays a seemingly opposite effect to transients in ERA-40 and a small ensemble-mean response with a large fluctuation among the AM2.1 realizations. As the result, the NH response to ENSO is not well projected onto the NAM. In the subtropics, the transient eddy momentum flux divergence moves poleward in both hemispheres, whereas anomalous stationary eddies strengthen the climatological stationary divergence at about $15^{\circ} \mathrm{N}$. From the perspective of angular momentum balance, the surface westerly movement linearly related to ENSO is mainly driven by transient eddies rather than by stationary eddies in the upper troposphere, although the momentum flux convergence is somewhat offset by the mountain torque in the $\mathrm{NH}$ (not shown).

We decompose the transient eddy momentum flux convergence at $250 \mathrm{hPa}$ as a function of latitude and angular phase speed for ERA-40 and the AM2.1 ensemble mean (Fig. 4). We use angular phase speed multiplied by the radius of the earth (phase speed divided by $\cos \phi$ ) in the plots to take the spherical geometry into account. As shown in Randel and Held (1991), the climatological means are characterized by eddy mo- 
ERA-40

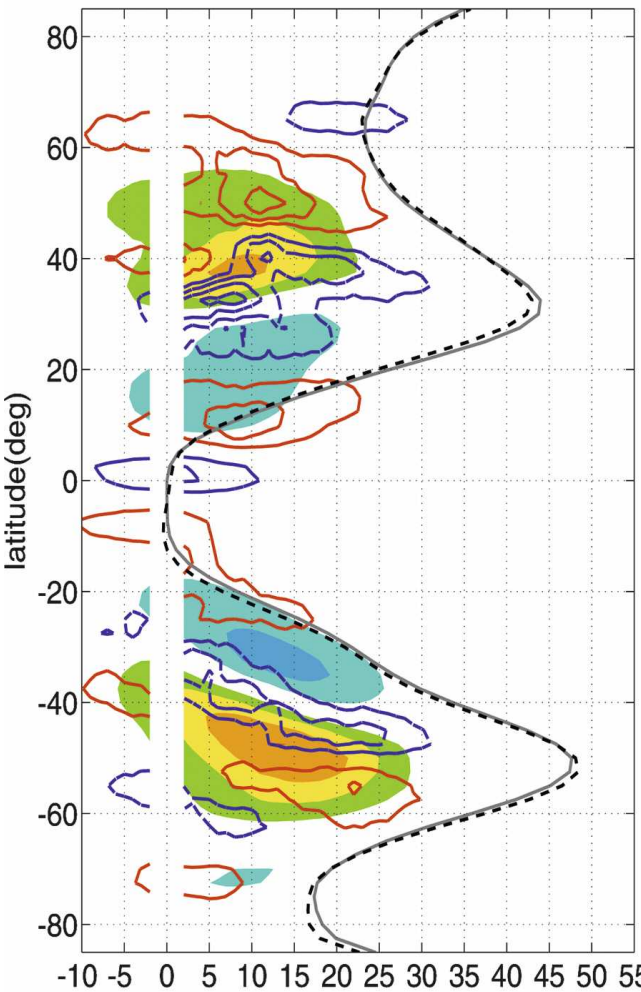

AM 2.1

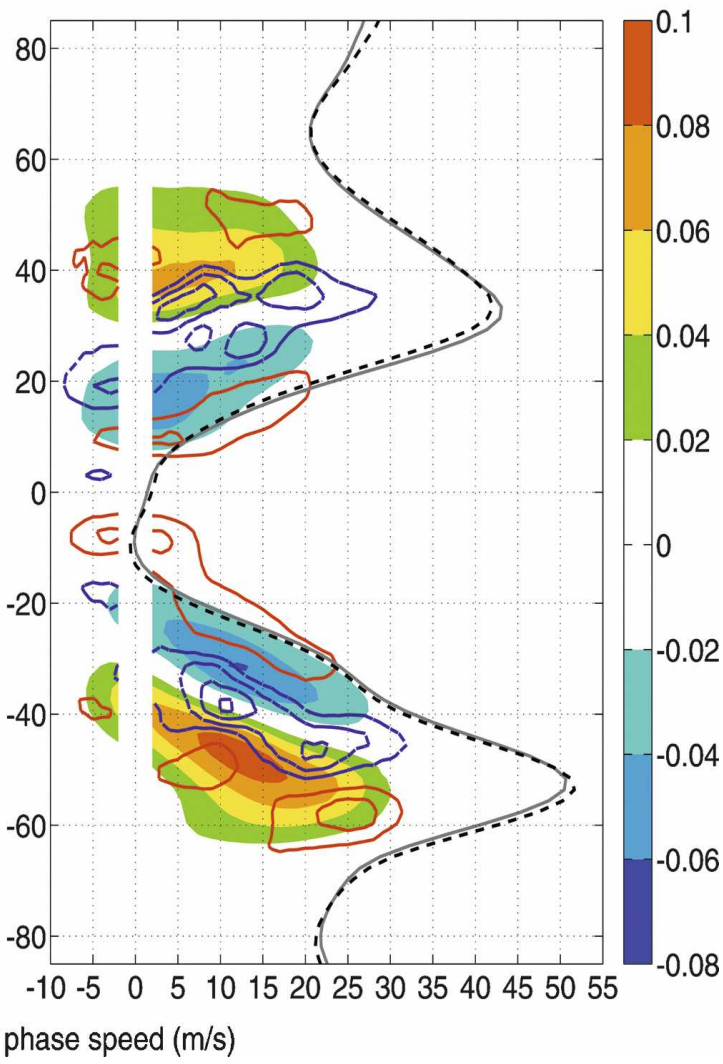

FIG. 4. The climatological means (shading) and La Niña-induced anomalies (contours) in the eddy momentum flux convergence at $250 \mathrm{hPa}$ in DJFM as a function of latitude and angular phase speed (multiplied by the earth's radius) for (left) ERA-40 and (right) the AM2.1 ensemble mean. The black solid lines denote the time and zonally averaged zonal winds at $250 \mathrm{hPa}$ divided by $\cos \phi$ for comparison, and the dashed lines denote winds under the La Niña condition. Contour intervals are $2 \times 10^{-3} \mathrm{~m} \mathrm{~s}^{-1}$ day ${ }^{-1}$; red (blue) color denotes the eddy momentum flux convergence (divergence).

mentum flux divergence in the subtropics and convergence in the midlatitudes, and the subtropical divergence is located slightly poleward of the critical latitudes. The anomalous ENSO-regressed spectra show a large hemispheric symmetry in the divergence and convergence anomalies in both the reanalysis and model. In the subtropics, the anomalous eddy momentum flux displays a meridional dipolar structure parallel to the subtropical critical line, implying a poleward shift of the subtropical momentum flux divergence. As is evident in the figure, the midlatitude eddies in the climatology can rarely penetrate beyond their critical latitudes, and thus the poleward shift of the subtropical divergence can be attributed to the weakening of subtropical winds during the cold ENSO phase, which prevents the equatorward penetration of midlatitude eddies. In the extratropics, the momentum flux convergence is displaced poleward, with strong anomalous convergence at about $50^{\circ} \mathrm{N}$ in the reanalysis. This displacement can be thought of as the result of either the poleward refraction of transient eddies (Seager et al. 2003) or the change of eddy life cycles due to the decreased surface baroclinicity (Orlanski 2003).

Since the model spectrum is similar to the observed but smoother due to a large ensemble of experiments, we further examine the transient eddy momentum flux within given latitude bands as a function of zonal wavenumber and phase speed for the AM2.1 ensemble mean (Fig. 5). The eddy spectra are area averaged over four latitude bands about the climatological mean midlatitude convergence and subtropical divergence maxima in the two hemispheres: $55^{\circ}-45^{\circ} \mathrm{S}, 35^{\circ}-25^{\circ} \mathrm{S}, 15^{\circ}-25^{\circ} \mathrm{N}$, and $35^{\circ}-45^{\circ} \mathrm{N}$. These averaged spectra thus represent the mean phase speeds and zonal wavenumbers of transient eddies being generated in the midlatitudes and absorbed in the subtropics. As these latitudes also roughly coincide with the anomalous eddy momentum flux maxima or minima, the averaged spectra capture 

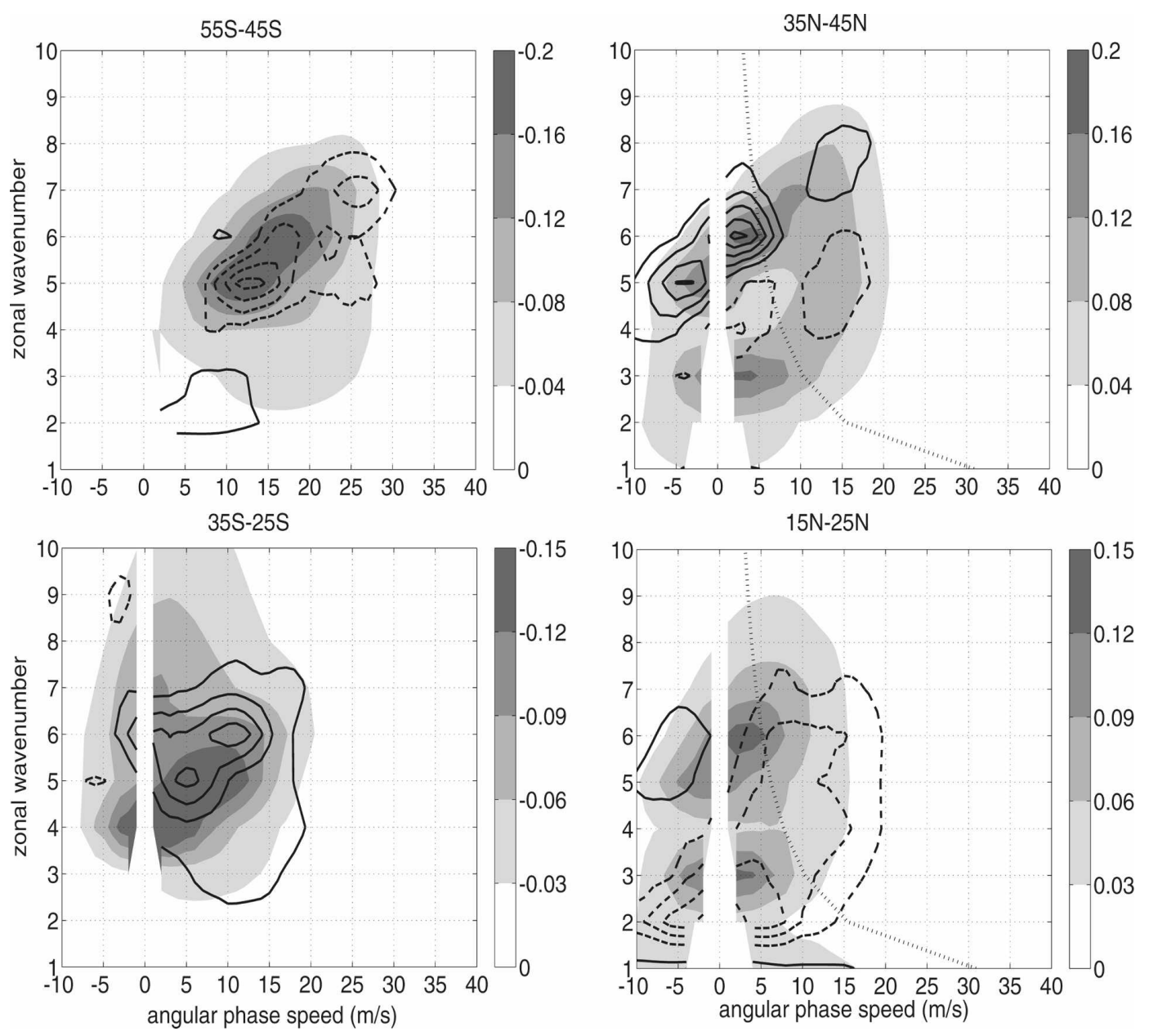

FIG. 5. The climatological means (shading) and La Niña-induced anomalies (contours) in the eddy momentum flux as a function of zonal wavenumber and angular phase speed at $250 \mathrm{hPa}$ in DJFM for the AM2.1 ensemble mean. The spectra are area averaged in the latitude bands (left) $55^{\circ}-45^{\circ} \mathrm{S}$ and $35^{\circ}-25^{\circ} \mathrm{S}$ and (right) $35^{\circ}-45^{\circ} \mathrm{N}$ and $15^{\circ}-25^{\circ} \mathrm{N}$. Contour intervals are $4 \times 10^{-3} \mathrm{~m}^{2} \mathrm{~s}^{-2}$; the solid (dashed) contours denote positive (negative) values, zeros omitted. Note that the eddy momentum flux has opposite signs in the two hemispheres and the negative (positive) eddy momentum flux anomalies in the SH represent the strengthening (weakening) of the climatological momentum flux pattern. The dotted line in the right panels denotes the period of 15 days in the spectral space.

the character of the eddies responsible for the anomalous movement of surface westerlies.

In the $\mathrm{SH}$, the climatological mean eddy spectra averaged in the midlatitudes $\left(55^{\circ}-45^{\circ} \mathrm{S}\right)$ are dominated by eddies with zonal wavenumbers 5-6 and angular phase speeds $10 \sim 20 \mathrm{~m} \mathrm{~s}^{-1}$, whereas the eddies averaged in the subtropics $\left(35^{\circ}-25^{\circ} \mathrm{S}\right)$ are predominantly wavenumbers $4-5$ and phase speeds $0 \sim 10 \mathrm{~m} \mathrm{~s}^{-1}$. Note that the negative (positive) eddy momentum flux anomalies in the $\mathrm{SH}$ represent the strengthening (weakening) of the climatological momentum flux pattern. The smaller phase speeds in the subtropics are expected since slower eddies can propagate farther equatorward than faster eddies. The La Niña-induced eddy anomalies averaged in the midlatitudes have nearly the same disper- sion characteristics as the dominant eddies generated in the climatology, although the intensity of the fastest and shortest waves is increased slightly. Meanwhile, the anomalous spectra averaged in the subtropics show a considerable reduction of eddies faster than the eddies typically reaching and being absorbed in these latitudes. Given the relatively small changes in the midlatitude where baroclinic eddies are generated and the substantial decreases in the subtropics where eddies are absorbed, this is consistent with the mechanism described in Seager et al. (2003), namely, that transient eddies are refracted poleward owing to the weakening of subtropical winds and the poleward shift of critical lines. Note that the increase in the fastest eddies with phase speeds $20 \sim 30 \mathrm{~m} \mathrm{~s}^{-1}$ in midlatitudes is related to 
the anomalous convergence at $55^{\circ} \mathrm{S}$ in the latitudephase speed spectra (Fig. 4) and that the overall increase in the momentum flux averaged between $55^{\circ}$ and $45^{\circ} \mathrm{S}$ may just reflect the poleward shift of the momentum flux, which has a peak at $\sim 35^{\circ} \mathrm{S}$ in the mean climate (Fig. 3).

The NH eddy response is analogous to the $\mathrm{SH}$ in some aspects but with more complexity. The climatological mean eddy spectra consist of medium-scale eddies of wavenumbers 5-6 and planetary-scale eddies of wavenumber 3 in both midlatitudes $\left(35^{\circ}-45^{\circ} \mathrm{N}\right)$ and subtropics $\left(15^{\circ}-25^{\circ} \mathrm{N}\right)$. In the midlatitudes, the medium-scale eddies extend in the wavenumber-phase speed space in a manner similar to the dispersion relationship in the SH (albeit with somewhat smaller phase speeds) and, therefore, are likely to be generated through baroclinic instability. The planetary-scale eddies, on the other hand, are quasi-stationary with phase speeds near zero. These are likely to be forced by zonal asymmetries in the lower boundary conditions such as topography or diabatic heating (see the review in Held et al. 2002). Note that these waves have a characteristic period longer than 15 days, indicated by the dotted line in the figure. In the La Niña anomalies, the mediumscale eddy response is similar to its SH counterpart, characterized by the weakening of faster eddies among all the disturbances arriving at the subtropics. There is also a poleward refraction of the midlatitude eddies implied by the wavenumber-phase speed distribution, roughly coincident with the climatological distribution. The planetary-scale eddy response in the model appears mainly in the subtropics, dominated by the weakening of eddy momentum flux transport by zonal wavenumber 2. This is consistent with the anomalous deceleration by stationary waves near $15^{\circ} \mathrm{N}$ in Fig. 3. The different responses in medium-scale and planetaryscale transient eddies may be attributed to the nature by which they are generated, but this is beyond the scope of this study.

\section{The internal variability}

We further explore the internal interannual variability in the surface westerlies and eddy spectra. More specifically, we refer to the internal variability as the extratropical wind variation independent of SST and radiative forcings, hence plausibly attributed to extratropical eddy-mean flow interaction. Although the observed annular mode variability can be partially explained by ENSO (L'Heureux and Thompson 2006), Limpasuvan and Hartmann (2000) demonstrate that the observed annular pattern can be well reproduced in an atmospheric GCM with fixed SST forcings. Here, to isolate the extratropical internal variability of the annular mode from the AM2.1 simulations forced by observed changes of SSTs and radiative agents, we subtract the ensemble mean response from each of the 10 simulation members. Regression is then conducted for each member between the resultant anomalous fields of interest and the detrended and standardized SWL index. The spatial pattern of the internal variability of the annular mode is finally attained by averaging over the 10 realizations.

Figure 6 shows the regression patterns of DJFM mean zonal wind anomalies at the surface and at 250 $\mathrm{hPa}$ for the internal variability in the two hemispheres. The zonal wind variability in both hemispheres displays a similar dipolar structure in latitude extending from the surface to the upper troposphere with the typical character of annular modes (cf. Limpasuvan and Hartmann 2000): the SH wind anomalies are nearly zonally symmetric at all levels and the $\mathrm{NH}$ wind anomalies become more zonally symmetric at the higher level. In contrast to the ENSO-induced zonal wind variability, the intrinsic wind variability is more zonally symmetric and restricted only in the midlatitudes of one hemisphere. This is especially clear in the NH, where ENSO is mainly linearly related to surface westerlies in the North Pacific, but the intrinsic wind variability shows a large response in both the North Pacific and North Atlantic.

The intrinsic surface wind anomalies are compared with anomalous eddy momentum fluxes in the upper troposphere. Figure 7 shows the ensemble mean patterns regressed onto the internal variability indices in the two hemispheres, for the DJFM and zonally averaged (bottom) surface stress, and the corresponding (top) transient and (middle) stationary eddy momentum flux convergence averaged between 100 and 500 $\mathrm{hPa}$. The figure also shows the ensemble spread over 10 realizations in shading. The internal variability of surface westerlies in the hemisphere of interest is characterized by the meridional vacillation about the westerly maximum, and the westerly anomalies in the other hemisphere are nearly zero in the ensemble mean, which is a key distinction from the hemispherically symmetric variability associated with ENSO.

While the intrinsic surface westerly anomalies in the $\mathrm{SH}$ are mainly driven by transient eddies in the upper troposphere, the intrinsic surface westerly anomalies in the $\mathrm{NH}$ are driven by both stationary and transient eddies. This is consistent with Limpasuvan and Hartmann (2000), who conclude that the stationary eddies, defined by monthly means, contribute significantly to the eddy momentum flux associated with the NAM. In comparison with the SST-forced response, the intrinsic 

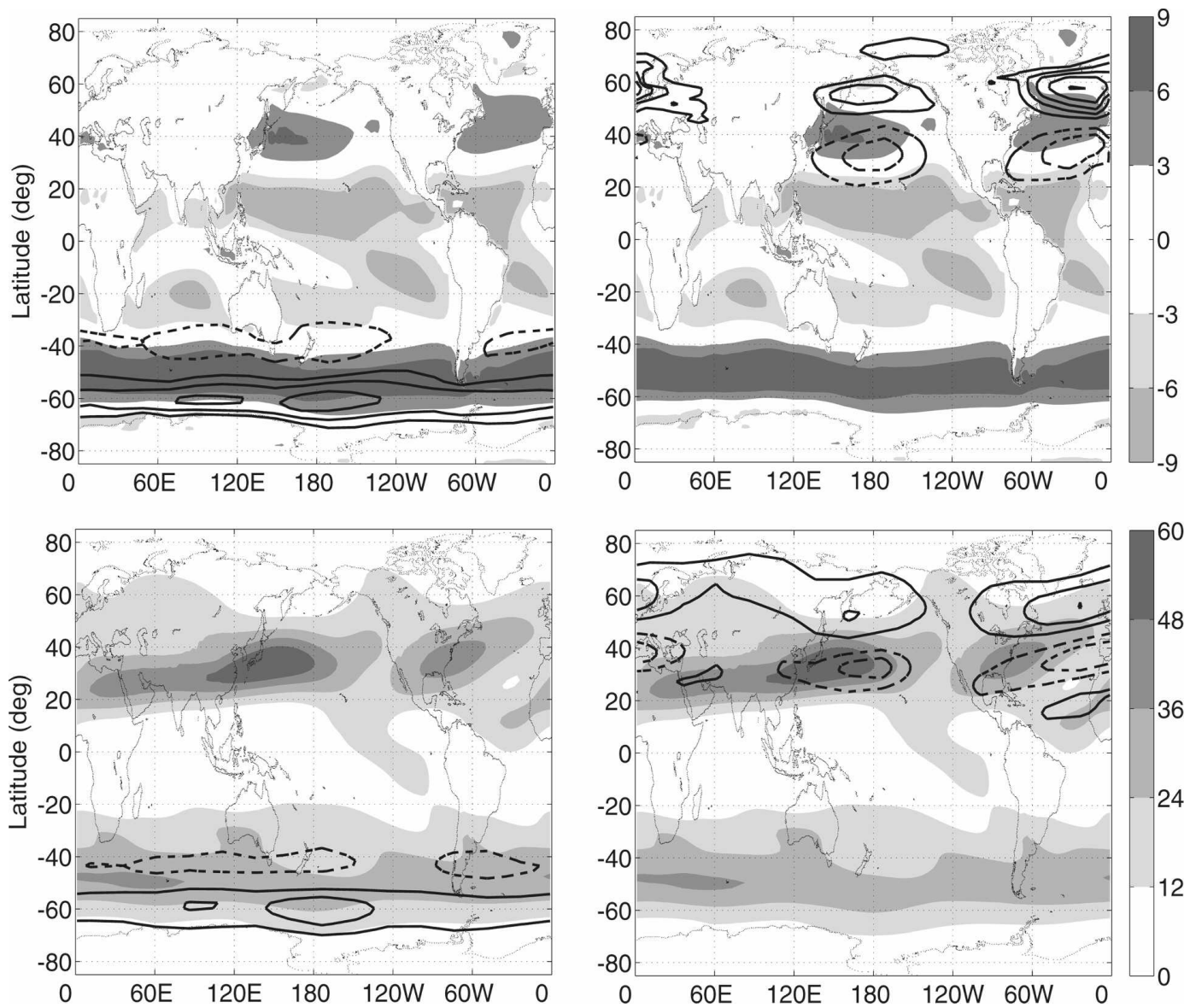

FIG. 6. As in Fig. 1 but for the DJFM mean zonal wind anomalies at (top) the surface and (bottom) $250 \mathrm{hPa}$ regressed onto the internal variability indices in the (left) SH and (right) NH in AM2.1. Shading represents the climatological mean winds; contours represent the anomalies associated with one standard deviation of the SWL index: intervals are (top) $0.3 \mathrm{~m} \mathrm{~s}^{-1}$ and (bottom) $1 \mathrm{~m} \mathrm{~s}^{-1}$.

transient momentum flux anomalies in the SH display a similar dipolar structure in midlatitudes, whereas the intrinsic convergence anomalies in the $\mathrm{NH}$ occur at higher latitudes. Moreover, the stationary eddies display an intrinsic momentum flux pattern in $\mathrm{NH}$ midlatitudes that appears not to be directly related with ENSO (cf. Figs. 3 and 7).

The transient eddy momentum flux convergence at $250 \mathrm{hPa}$ is plotted as a function of latitude and angular phase speed (Fig. 8). In the SH, the intrinsic eddy momentum flux anomalies mark the divergence at $40^{\circ} \mathrm{S}$ and convergence at $60^{\circ} \mathrm{S}$, both associated with eddy phase speeds between 15 and $25 \mathrm{~m} \mathrm{~s}^{-1}$. In the $\mathrm{NH}$, there is a noticeable anomalous divergence maximum at $\sim 35^{\circ} \mathrm{N}$ with phase speeds between 10 and $20 \mathrm{~m} \mathrm{~s}^{-1}$, and the anomalous convergence maximum is less well defined and spans the latitudes from $50^{\circ}$ to $70^{\circ} \mathrm{N}$. The zonally averaged convergence anomalies (Fig. 7) exhibit a peak value at $60^{\circ} \mathrm{N}$, which can be attributed to the eddies with phase speeds between 0 and $10 \mathrm{~m} \mathrm{~s}^{-1}$. Therefore, the phase speed spectra illustrate a distinction between the eddies associated with the internal dynamics in the two hemispheres: While the SH intrinsic variability is mainly associated with faster eddies in the climatological spectra, the NH intrinsic variability involves all of the eddies maintaining the mean climate.

The transient eddy momentum flux at $250 \mathrm{hPa}$ is further examined in the zonal wavenumber-phase speed space (Fig. 9). We only show the averages over the midlatitudes where most of the anomalies are seen in Fig. 8. In the SH, the eddy momentum flux anomalies averaged in midlatitudes $\left(55^{\circ}-45^{\circ} \mathrm{S}\right)$, in the positive phase of internal variability, are characterized by a coherent spectral structure with a marked increase in phase speed and a small change in zonal wavenumber. In the $\mathrm{NH}$, the medium-scale and planetary-scale eddies averaged in midlatitudes $\left(35^{\circ}-45^{\circ} \mathrm{N}\right)$ display two distinct regression patterns. The anomalous medium- 

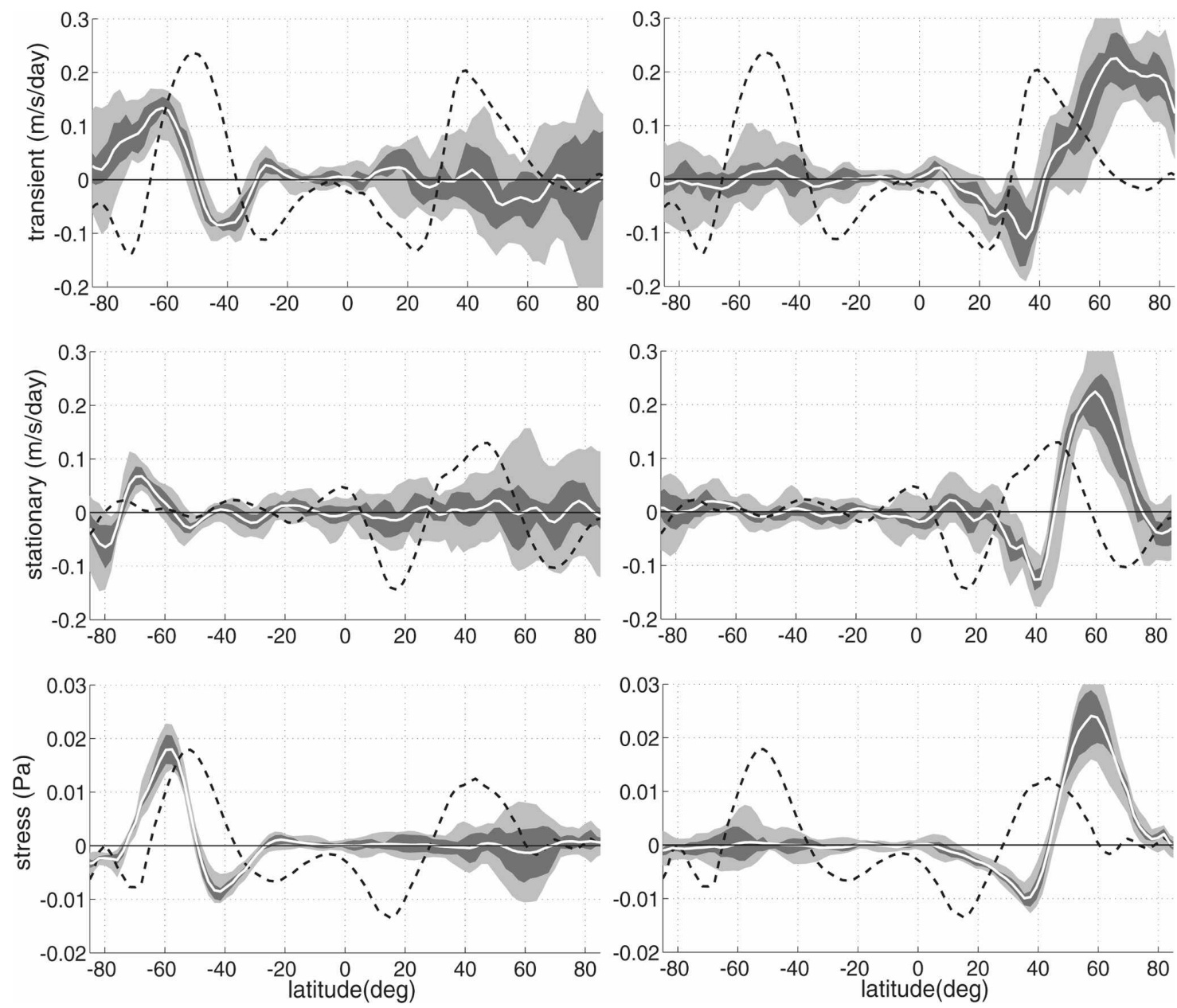

FIG. 7. As in Fig. 3 but for the internal variability in the upper tropospheric eddy momentum flux convergence and surface stress with the spread among 10 realizations in the (left) $\mathrm{SH}$ and (right) NH in AM2.1. The white solid lines are the regression patterns of the (bottom) surface stress and the corresponding (top) transient and (middle) stationary eddy momentum flux convergence averaged between 100 and $500 \mathrm{hPa}$; dashed lines are 1/10 of the climatological means. The model ensemble spread is ranked and plotted in gray shading as in Fig. 2.

scale eddies have characteristic phase speeds between 10 and $20 \mathrm{~m} \mathrm{~s}^{-1}$, and the comparison with Figs. 7 and 8 indicates that the associated eddy forcing is well projected onto the surface wind vacillation, as for the $\mathrm{SH}$ counterpart. However, the anomalous planetary-scale eddies are dominated by eddies with nearly zero phase speeds, and the comparison with Figs. 7 and 8 suggests that they are largely responsible for the anomalous convergence at $60^{\circ} \mathrm{N}$. This connection can be seen more clearly in the eddy spectrum averaged between $45^{\circ}$ and $55^{\circ} \mathrm{N}$ (not shown). The anomalous planetary-scale transient eddies have similar phase speeds and wavenumbers to the climatological means, consistent with the notion that these eddies are refracted poleward in the positive phase of the NAM (Limpasuvan and Hartmann 2000; Lorenz and Hartmann 2003).

The phase speed spectrum provides detailed infor- mation on eddy characteristics related to the internal variability. For example, the anomalous medium-scale and planetary-scale eddies in the $\mathrm{NH}$ reveal two distinct time scales roughly separated by a 15 -day period, which was employed as a cutoff period in Lorenz and Hartmann (2003) for the high-frequency eddies associated with the NAM variability. Moreover, the spectra provide new insights into the annular mode variability: The positive phase of annular modes is associated with increased phase speeds of medium-scale eddies, as well as the poleward shift in the propagation and absorption of Rossby waves in the upper troposphere, although the eddy spectrum alone cannot settle the causality relationship between the phase of annular modes and the variability of wave activity.

The eddy phase spectrum also reveals the difference between the intrinsic and ENSO-forced variability. Al- 

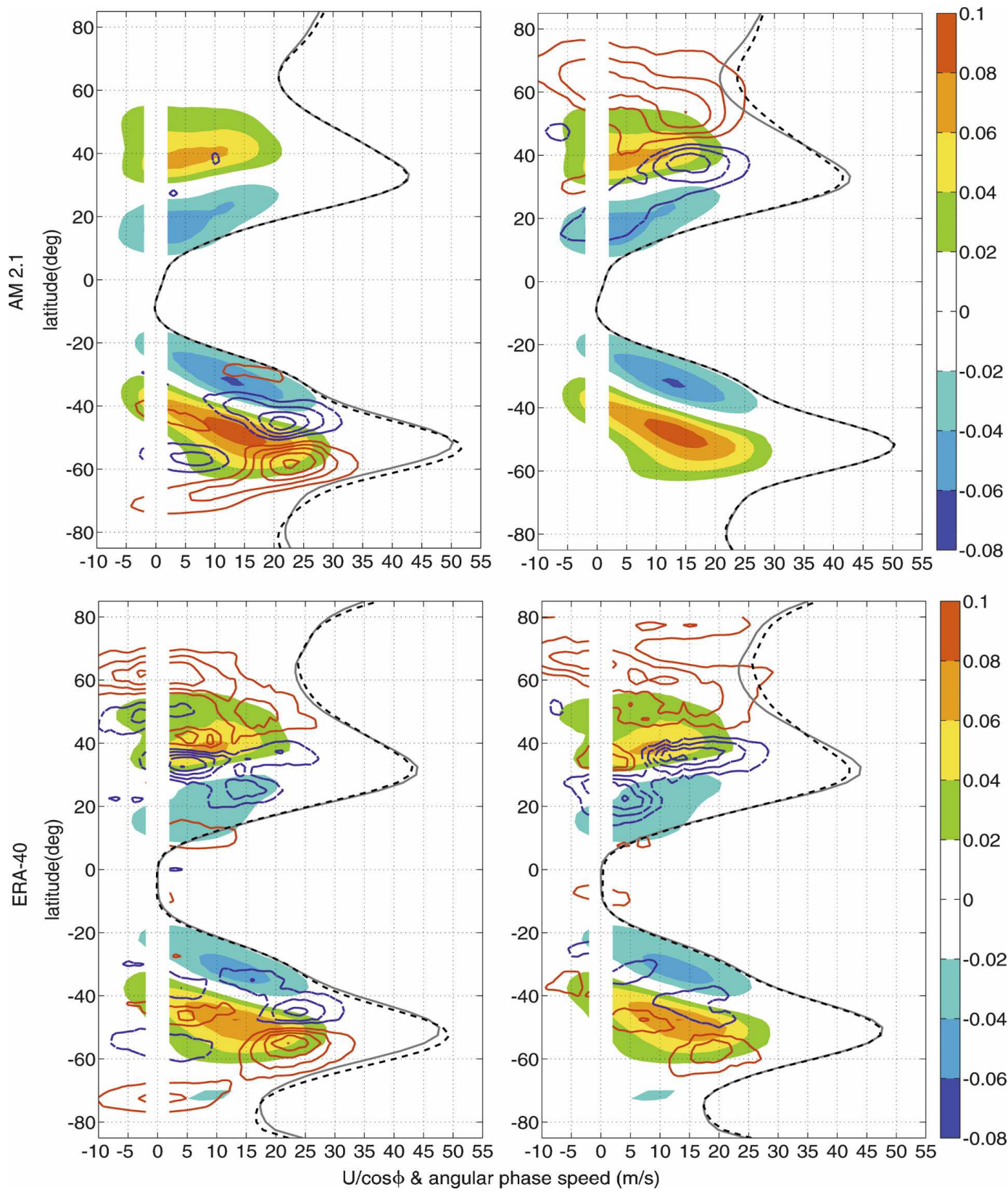

FIG. 8. As in Fig. 4 but for the climatological means (shading) and internal variability patterns (contours) in the eddy momentum flux convergence at $250 \mathrm{hPa}$ in DJFM, as a function of latitude and angular phase speed in (top left) the $\mathrm{SH}$ and (top right) $\mathrm{NH}$ in AM2.1. The bottom panels are the corresponding regression patterns about the detrended and standardized SWL indices in ERA-40. Black solid lines denote the time and zonally averaged zonal winds at $250 \mathrm{hPa}$ divided by $\cos \phi$ for comparison; dashed lines denote the winds in the positive phase of the annular mode: contour intervals are $2 \times 10^{-3} \mathrm{~m} \mathrm{~s}^{-1}$ day $^{-1}$. The red (blue) color denotes the eddy momentum flux convergence (divergence).

though the intrinsic eddy variability occurs mostly in the midlatitude convergence and in the eddies faster than typical eddies in the mean climate, the ENSOinduced change occurs largely in the subtropical divergence and in nearly all phase speeds, especially in the AM2.1 ensemble mean; albeit the ENSO signal extends up to $60^{\circ} \mathrm{S} / 50^{\circ} \mathrm{N}$, which is more likely due to the eddy feedbacks to the poleward jet movement rather than to the direct response to tropical forcing. For the mediumscale eddies in the midlatitudes, the positive phase of internal variability is best described as a poleward shift associated with increased eddy phase speeds, but the 

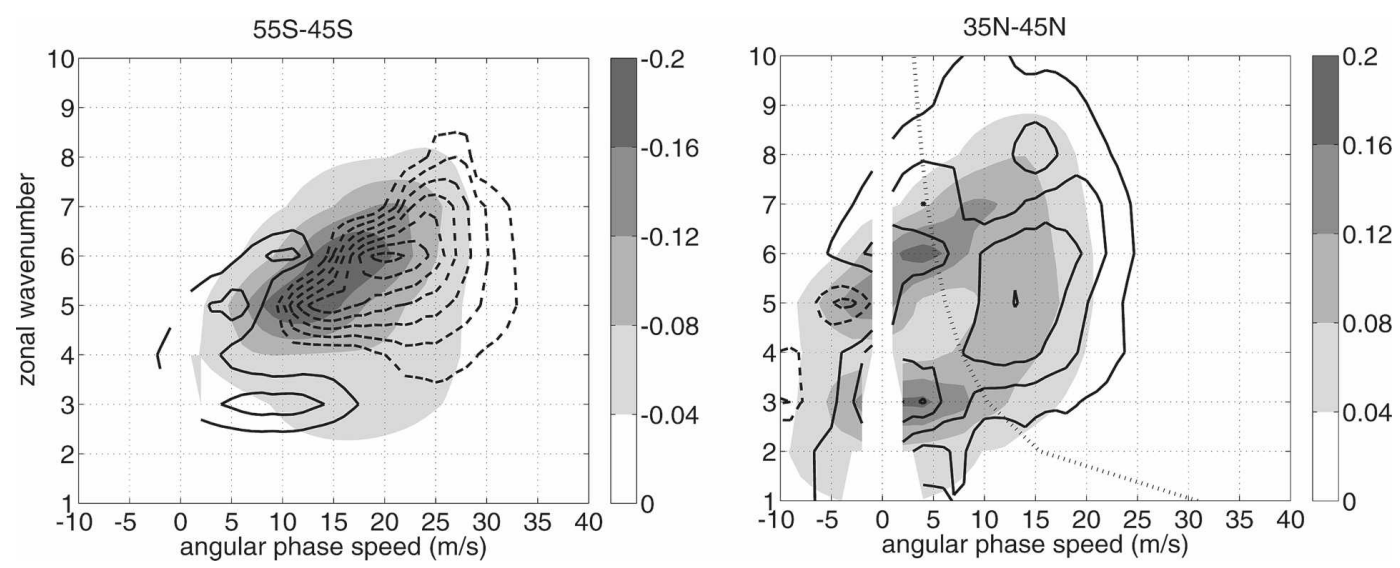

FIG. 9. As in Fig. 5 but for the (shading) climatological means and (contours) internal variability patterns in the eddy momentum flux as a function of zonal wavenumber and angular phase speed at $250 \mathrm{hPa}$ in DJFM in the (left) $\mathrm{SH}$ and (right) $\mathrm{NH}$ in $\mathrm{AM} 2.1$. The spectra are area averaged in the latitude bands (left) $55^{\circ}-45^{\circ} \mathrm{S}$ and (right) $35^{\circ}-45^{\circ} \mathrm{N}$. Contour intervals are $4 \times 10^{-3} \mathrm{~m}^{2} \mathrm{~s}^{-2}$; solid (dashed) contours denote positive (negative) values, zeros omitted. Note that the eddy momentum flux has opposite signs in the two hemispheres. The dotted line in the right panels denotes the period of 15 days in the spectral space.

ENSO response displays relatively little change (except for those anticipated from eddy feedbacks) in the character of eddies in midlatitudes, consistent with a poleward refraction by the subtropical wind anomalies.

We have attempted to compute the patterns of internal variability in the reanalysis. The lower panels of Fig. 8 show the phase speed spectrum anomalies regressed onto the detrended and standardized SWL in ERA-40. The eddy spectrum anomalies in the reanalysis are similar to those in the model in several ways, including increased convergence and divergence associated with eddies of phase speeds between 15 and $30 \mathrm{~m} \mathrm{~s}^{-1}$ in the $\mathrm{SH}$ and anomalies over a wide range of phase speeds in the NH. However, the signals in the reanalysis are noisier than those in the model, and there are minor yet discernable signals outside the hemisphere in question, especially in the $\mathrm{NH}$ of the regression pattern about the SH surface westerly variability, which we attribute to the insufficiency of independent events in calculating the full space-time spectrum of eddies. To obtain the structure of intrinsic variability, one would additionally need to eliminate influences from major ENSO and volcanic events, and thus independent samples would be even smaller. Therefore, we leave out a thorough comparison between the reanalysis and the model in this section although the regression patterns of zonally averaged fields are fairly similar.

\section{The global warming trend}

In this section, we study the responses to global warming (IPCC A2 scenario) in the latitude of surface westerlies and the eddy spectra in CM2.1 and compare them with the ENSO-induced and intrinsic interannual variability. Figure 10 shows the spatial pattern of the DJFM mean zonal wind response at the surface and at $250 \mathrm{hPa}$. The surface westerlies are displaced poleward in both hemispheres, and the wind anomalies have a zonally symmetric component that resembles those in the internal variability case more than in the ENSOinduced variability. The resemblance becomes less in the upper troposphere. In the $\mathrm{SH}$, the midlatitude jet moves poleward with anomalous westerlies in the subtropics, analogous to the separation of the eddy-driven jet from the subtropical jet in idealized models, as the equator-to-pole temperature gradients or water vapor contents are altered (e.g., Son and Lee 2005; Frierson et al. 2006, 2007a). In the NH, the zonal wind response is less clear on the equatorward flank of the Pacific and Atlantic jets, whereas the zonal wind on the poleward flank is intensified and more zonally symmetric.

We next examine the upper-tropospheric momentum flux responses associated with the displacement of surface westerlies. Figure 11 shows the responses for the DJFM and zonally averaged (bottom) surface stress, and the corresponding (top) transient and (middle) stationary eddy momentum flux convergence averaged between 100 and $500 \mathrm{hPa}$. From the angular momentum balance, the surface wind shift in the $\mathrm{SH}$ is mainly driven by transient eddy momentum fluxes, but for the surface westerly movement in the $\mathrm{NH}$, both transient and stationary eddies are important. Although the transient eddy response in the two hemispheres displays a poleward shift similar to the positive phase of internal 

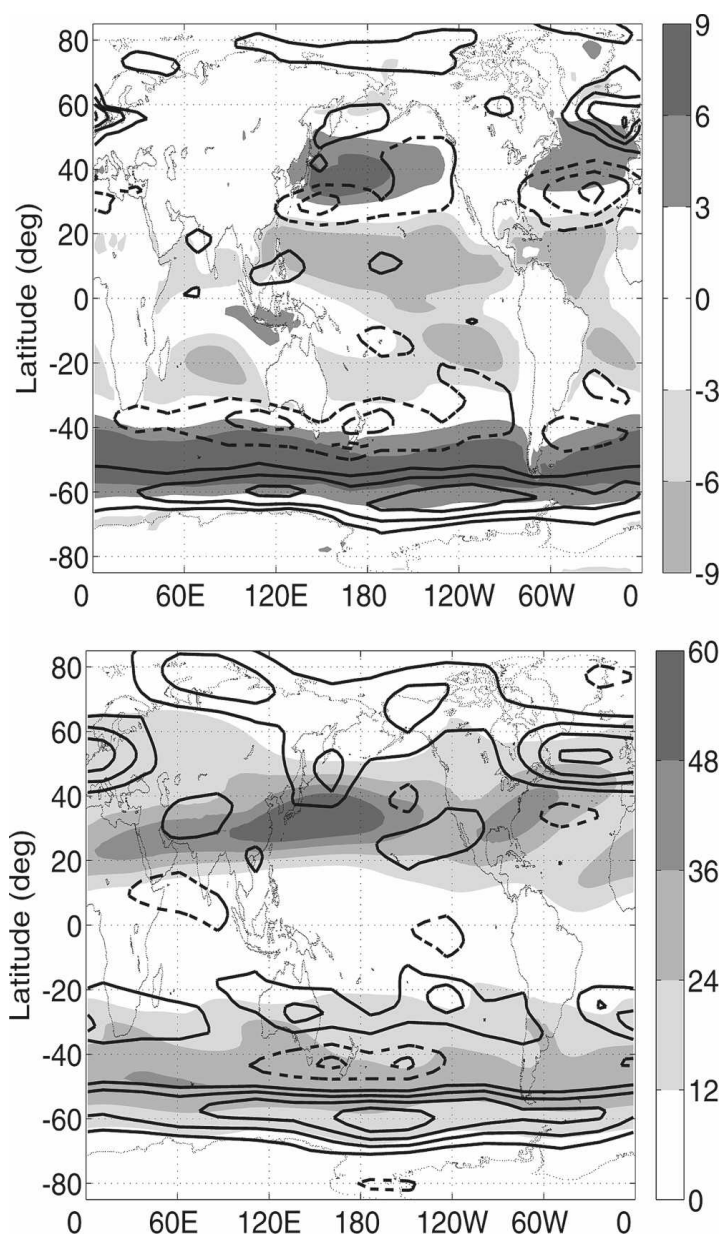

FIG. 10. As in Fig. 1 but for the zonal wind responses under global warming at (top) the surface and (bottom) $250 \mathrm{hPa}$. Shading represents the climatological mean winds; contour intervals are (top) $0.6 \mathrm{~m} \mathrm{~s}^{-1}$ and (bottom) $1.5 \mathrm{~m} \mathrm{~s}^{-1}$.

variability, the stationary eddy response in the $\mathrm{NH}$ is more of a weakening than of a shift relative to the climatological mean (Joseph et al. 2004). Moreover, the anomalous stationary momentum flux convergence at about $40^{\circ} \mathrm{N}$ is not very well defined.

The response of the transient eddy momentum flux convergence at $250 \mathrm{hPa}$ is plotted in the latitude-phase speed spectrum (Fig. 12). In the SH, both the eddy momentum flux convergence and divergence increase for phase speeds between 15 and $30 \mathrm{~m} \mathrm{~s}^{-1}$ and decrease somewhat for phase speeds between 0 and $15 \mathrm{~m} \mathrm{~s}^{-1}$. The decrease in the subtropical divergence between $20^{\circ}$ and $40^{\circ} \mathrm{S}$ is related to the subtropical westerly anomalies in Fig. 10. In the NH, the subtropical divergence and midlatitude convergence, like their $\mathrm{SH}$ counterparts, display an increase in phase speed from $-5 \sim 5$ $\mathrm{m} \mathrm{s}^{-1}$ to $10 \sim 20 \mathrm{~m} \mathrm{~s}^{-1}$ except there is anomalous convergence by planetary-scale eddies at about $60^{\circ} \mathrm{N}$. The
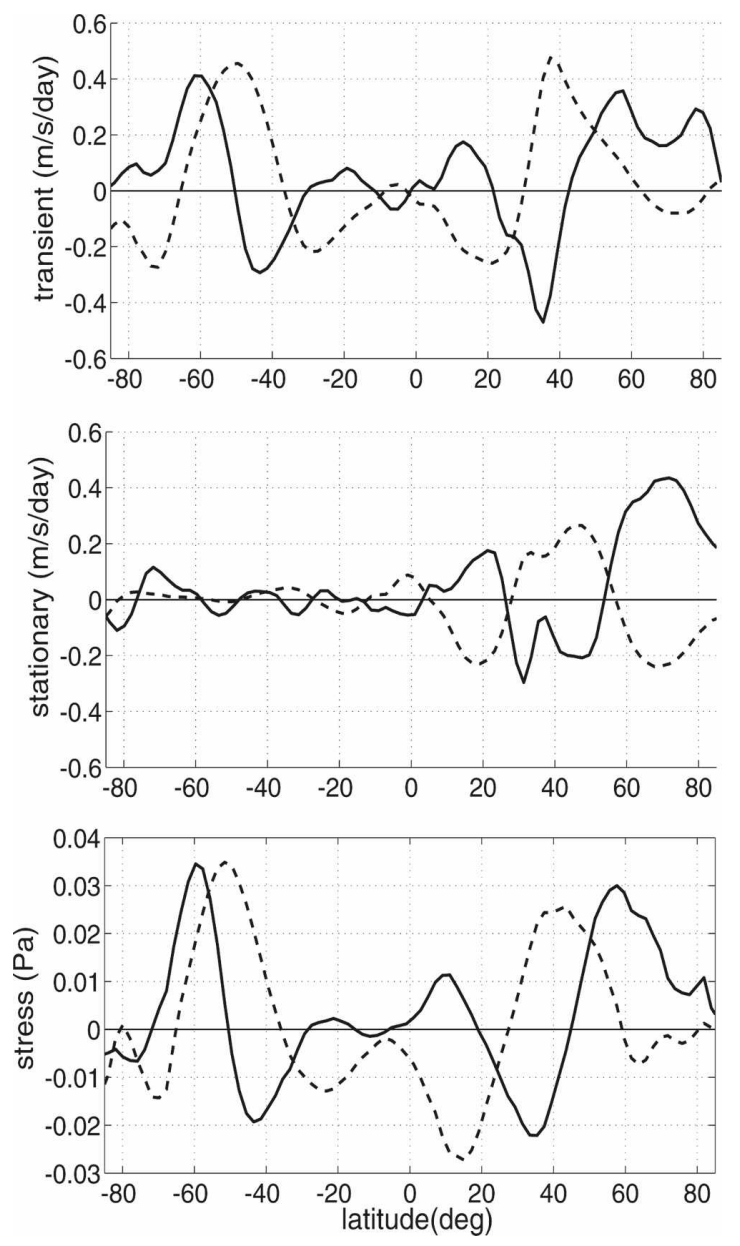

FIG. 11. As in Fig. 3 but for the responses under global warming in the upper tropospheric eddy momentum flux convergence and surface stress. Black solid lines are the responses of the (bottom) surface stress and the corresponding (top) transient and (middle) stationary eddy momentum flux convergence averaged between 100 and $500 \mathrm{hPa}$; dashed lines are $1 / 5$ of the climatological means.

response in the planetary-scale transient eddies corresponds to the weakening of stationary waves in Fig. 11. In both hemispheres, the increases in eddies with faster phase speeds are remarkably similar to the anomalous patterns in the positive phase of internal variability; however, in the response to global warming, the decreases in slower phase speeds become noticeable as well. As the subtropical critical latitude of midlatitude eddies tilts poleward for more rapid eastward propagation, the increased eddy phase speeds are accompanied by a poleward shift of the subtropical momentum flux divergence.

The transient eddy momentum flux at $250 \mathrm{hPa}$ is again plotted in the wavenumber-phase speed spectra averaged about the anomalous eddy flux maxima and minima (Fig. 13). In the SH, the eddy momentum flux 


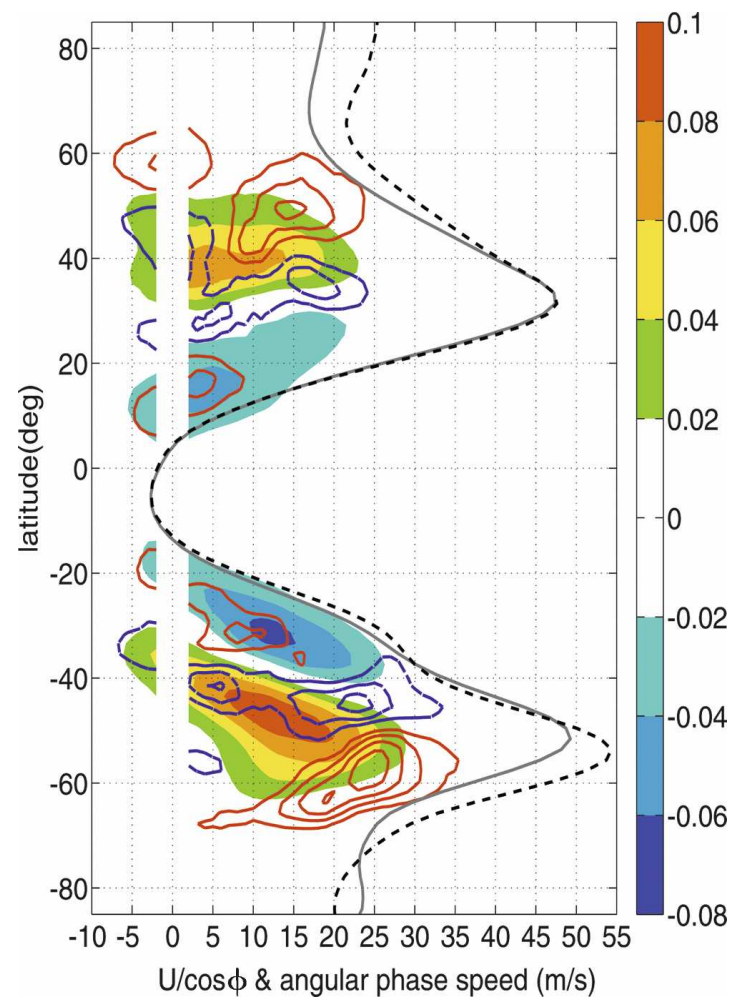

FIG. 12. As in Fig. 4 but for the climatological mean (shading) and the global warming response (contours) in the eddy momentum flux convergence at $250 \mathrm{hPa}$ in DJFM as a function of latitude and angular phase speed. Black solid lines denote the time and zonally averaged zonal winds at $250 \mathrm{hPa}$ divided by $\cos \phi$ for comparison; dashed lines denote the winds under global warming: Contour intervals are $6 \times 10^{-3} \mathrm{~m} \mathrm{~s}^{-1} \mathrm{day}^{-1}$. The red (blue) color denotes the eddy momentum flux convergence (divergence).

averaged in the midlatitudes $\left(55^{\circ}-45^{\circ} \mathrm{S}\right)$ displays an increase in phase speed with little change in wavenumber, roughly following the slope of the dispersion relationship in the time mean. The change in phase speed is also evident in the subtropics $\left(35^{\circ}-25^{\circ} \mathrm{S}\right)$ where the dominant eddies are slower than those diverging from the midlatitudes, and the response of subtropical eddies can be roughly traced back to their midlatitude origins. In the $\mathrm{NH}$, the medium-scale eddies respond to global warming by a similar increase in phase speed in the subtropics $\left(15^{\circ}-25^{\circ} \mathrm{N}\right)$ and midlatitudes $\left(35^{\circ}-45^{\circ} \mathrm{N}\right)$, although the pattern is less well defined. For the mediumscale eddies in both hemispheres, the increased momentum fluxes at faster phase speeds are similar to those in the positive phase of internal variability, but the decreased momentum fluxes at slower phase speeds become more noticeable in the global warming response. The planetary-scale eddies also show an increased poleward momentum flux transport in midlatitudes by zonal wavenumber 2 , which corresponds to the anomalous convergence in $60^{\circ} \mathrm{N}$ in Fig. 12 and is more notable if the spectrum is averaged between $45^{\circ}$ and $55^{\circ} \mathrm{N}$ (not shown).

\section{Conclusions and discussion}

In this paper, we have identified and compared the characteristics of surface wind changes and associated anomalous eddy momentum flux spectra: during the cold phase of the ENSO cycle in the reanalysis and GFDL atmosphere-only climate model, for the positive phase of the internal annular modes in the atmosphere model, and under global warming in the coupled atmosphere-ocean model.

Despite the fact that the cold phase of the ENSO cycle can project significantly upon the positive phase of the SAM, the ENSO-induced changes display patterns in the eddy momentum flux spectra distinct from those associated with the intrinsic annular mode variability. The response to ENSO is characterized by a meridional shift of the critical latitudes of the equatorward propagating eddies, a picture consistent with the refraction of midlatitude eddies due to the subtropical wind anomalies, as discussed by Seager et al. (2003), whereas the internal variability marks a change in the eastward propagation speed of midlatitude eddies. Interestingly, the model response to global warming bears a remarkable resemblance to the annular mode of the respective hemisphere. Moreover, the response in eddy momentum flux spectra exhibits a trend toward faster eddy phase speeds in both hemispheres, in a manner similar to the positive phase of the internal variability. This suggests that the annular mode trend due to greenhouse gas increases may be more related to the processes associated with the extratropical internal variability such as the wind or temperature anomalies in the upper troposphere/lower stratosphere, rather than being forced from deep tropics, especially in view of the contrast between the robustness of the annular-modelike midlatitude response versus the great uncertainties in the tropical diabatic processes (see the IPCC WG1 AR4 report at http://ipcc-wg1.ucar.edu/wg1/wg1-report. html).

It is also of interest to observe that ENSO can excite a pattern that projects only significantly on the SAM, but not the NAM, whereas the global warming can excite both SAM- and NAM-like responses. Obviously, the zonal asymmetry in the land-sea distribution matters to the teleconnection from the tropics to middle and high latitudes. Meanwhile, this result hints that there are elements in the atmospheric forcing of the global warming case that are not completely undermined by the barriers of land-one of the probable 

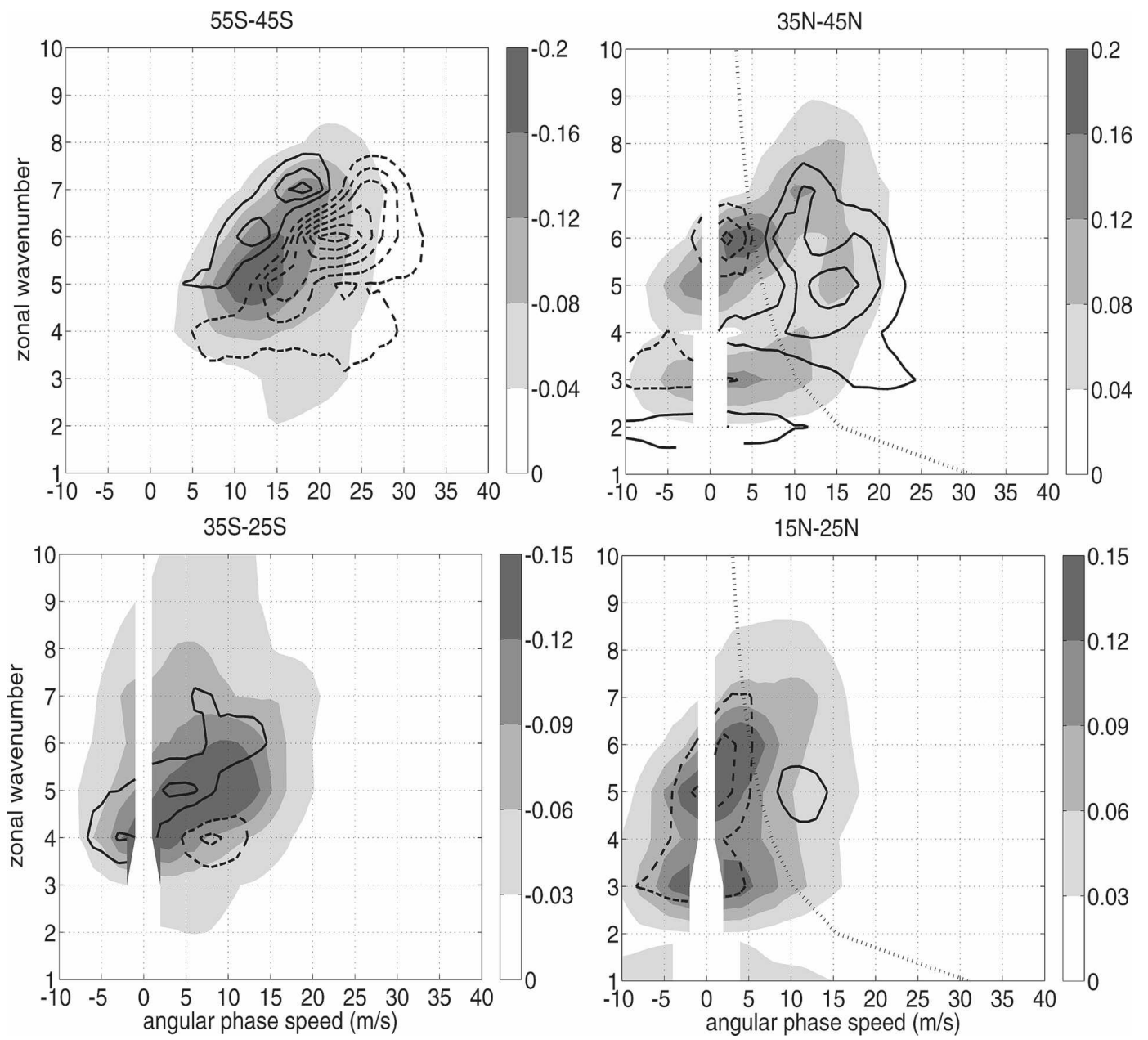

FIG. 13. As in Fig. 5 but for the climatological means (shading) and global warming responses (contours) in the eddy momentum flux as a function of zonal wavenumber and angular phase speed at $250 \mathrm{hPa}$ in DJFM. The spectra are area averaged in the latitude bands (left) $55^{\circ}-45^{\circ} \mathrm{S}$ and $35^{\circ}-25^{\circ} \mathrm{S}$ and (right) $35^{\circ}-45^{\circ} \mathrm{N}$ and $15^{\circ}-25^{\circ} \mathrm{N}$. Contour intervals are $0.02 \mathrm{~m}^{2} \mathrm{~s}^{-2}$; solid (dashed) contours denote positive (negative) values, zeros omitted. Note that the eddy momentum flux has opposite signs in the two hemispheres. The dotted line in the right panels denotes the period of 15 days in the spectral space.

candidates is the radiative forcing by the greenhouse gases at the upper troposphere and the lower stratosphere (C. Deser 2007, personal communication).

Recently, Lorenz and DeWeaver (2007) find that the poleward shift of zonal winds in IPCC models is associated with an increase in the tropopause height and show that similar changes in circulation can be simulated in a simple GCM when the tropopause height is raised by directly cooling the stratosphere. This reproduces the results in Williams (2006), who argues that it is through changing the eddy scale that the tropopause height influences the position of the tropospheric jet. Here, our space-time spectral analysis, instead, suggests that the changes in eddy momentum fluxes are more likely due to increases in eddy phase speeds in the GFDL coupled model.
Furthermore, Chen and Zurita-Gotor (2008) show that increased extratropical stratospheric winds can lead to a poleward shift in the tropospheric jet through an increase in the eastward propagation of tropospheric eddies in a similar simple GCM. Therefore, the projected jet shifts in both hemispheres under global warming may be explained, at least in part, as a consequence of increased zonal winds in the lower stratosphere, due to upper tropospheric warming and lower stratospheric cooling and the tropopause slope. These increased winds may accelerate the eastward phase speeds of midlatitude eddies, resulting in a poleward shift of the eddy momentum flux convergence and the associated surface winds, analogous to the interpretations for the positive annular trend due to stratospheric ozone depletion (Chen and Held 2007). Lorenz and 
DeWeaver (2007) also show that the ensemble mean zonal wind response in IPCC models is significantly correlated with cooling over the polar cap in the lower stratosphere, consistent with the importance of the subpolar lower stratospheric winds.

On the other hand, the tropical-extratropical interaction can still play an important role in generating a poleward shift of surface westerlies. Lu et al. (2008) show that expansion of the Hadley cell is significantly correlated with the poleward shift of surface westerlies in boreal winter/austral summer. It is argued that the increase in static stability of the subtropical and midlatitude troposphere, a result of the quasi-moist-adiabatic adjustment to the surface warming, can stabilize the eddy growth on the equatorward side of the storm track and plausibly push the eddy activity and the associated surface westerlies poleward (see also Lu et al. 2007; Frierson et al. 2007b). It remains a challenge to quantify and discriminate the contributions to the annular mode trend due to the lower stratospheric wind anomalies and tropospheric static stability changes. We are currently designing and performing idealized model experiments to further address this issue.

Acknowledgments. We thank Isaac Held, Isidoro Orlanski, Alan Plumb, and Steve Garner for valuable discussions and three anonymous reviewers for helpful comments that improved the manuscript. We also thank Thomas Delworth for access to GFDL AM2.1 runs. The ERA-40 reanalysis data were provided by the Data Support Section of the Scientific Computing Division at the National Center for Atmospheric Research, and the assistance is greatly appreciated. GC is supported by the NOAA Climate and Global Change Postdoctoral Fellowship, administered by the University Corporation for Atmospheric Research. GC is also partially supported by National Science Foundation Grant ATM-0808831. JL is supported by the Advanced Study Program at NCAR.

\section{REFERENCES}

Abatzoglou, J. T., and G. Magnusdottir, 2006: Planetary wave breaking and nonlinear reflection: Seasonal cycle and interannual variability. J. Climate, 19, 6139-6152.

Anderson, J., and Coauthors, 2004: The new GFDL global atmosphere and land model AM2/LM2: Evaluation with prescribed SST simulations. J. Climate, 17, 4641-4673.

Arblaster, J. M., and G. A. Meehl, 2006: Contributions of external forcings to southern annular mode trends. J. Climate, 19, 2896-2905.

Cash, B. A., P. J. Kushner, and G. K. Vallis, 2002: The structure and composition of the annular modes in an aquaplanet general circulation model. J. Atmos. Sci., 59, 3399-3414.

Chang, E. K. M., 1995: The influence of Hadley circulation inten- sity changes on extratropical climate in an idealized model. $J$. Atmos. Sci., 52, 2006-2024.

1998: Poleward-propagating angular momentum perturbations induced by zonally symmetric heat sources in the tropics. J. Atmos. Sci., 55, 2229-2248.

Chen, G., 2007: Mechanisms that control the latitude of jet streams and surface westerlies. Ph.D. thesis, Princeton University, $153 \mathrm{pp}$.

— poleward shift of Southern Hemisphere surface westerlies. Geophys. Res. Lett., 34, L21805, doi:10.1029/2007GL031200.

— prescribed zonal forcing in an idealized atmospheric model. $J$. Atmos. Sci., 65, 2254-2271.

Delworth, T. L., and Coauthors, 2006: GFDL's CM2 global coupled climate models. Part I: Formulation and simulation characteristics. J. Climate, 19, 643-674.

Deser, C., and J. M. Wallace, 1990: Large-scale atmospheric circulation features of warm and cold episodes in the tropical Pacific. J. Climate, 3, 1254-1281.

Feldstein, S., and S. Lee, 1996: Mechanisms of zonal index variability in an aquaplanet GCM. J. Atmos. Sci., 53, 3541-3556.

Frierson, D. M. W., I. M. Held, and P. Zurita-Gotor, 2006: A gray-radiation aquaplanet moist GCM. Part I: Static stability and eddy scale. J. Atmos. Sci., 63, 2548-2566.

,$- \ldots$, and $\longrightarrow, 2007 \mathrm{a}:$ A gray-radiation aquaplanet moist GCM. Part II: Energy transports in altered climates. J. Atmos. Sci., 64, 1680-1693.

— , J. Lu, and G. Chen, 2007b: Width of the Hadley cell in simple and comprehensive general circulation models. Geophys. Res. Lett., 34, L18804, doi:10.1029/2007GL031115.

Fyfe, J., G. Boer, and G. Flato, 1999: The Arctic and Antarctic Oscillations and their projected changes under global warming. Geophys. Res. Lett., 26, 1601-1604.

Gillett, N. P., and D. W. J. Thompson, 2003: Simulation of recent Southern Hemisphere climate change. Science, 302, 273-275.

Hartmann, D. L., and F. Lo, 1998: Wave-driven zonal flow vacillation in the Southern Hemisphere. J. Atmos. Sci., 55, 1303 1315.

Hayashi, Y., 1971: A generalized method of resolving disturbances into progressive and retrogressive waves by space Fourier and time cross-spectral analyses. J. Meteor. Soc. Japan, 49, 125-128.

Held, I. M., 1985: Pseudomomentum and the orthogonality of modes in shear flows. J. Atmos. Sci., 42, 2280-2288.

- 2000: The general circulation of the atmosphere. Proc. Program in Geophysical Fluid Dynamics, Woods Hole, MA, Woods Hole Oceanographic Institution, 1-36.

— M. Ting, and H. Wang, 2002: Northern winter stationary waves: Theory and modeling. J. Climate, 15, 2125-2144.

Hoskins, B. J., and D. J. Karoly, 1981: The steady linear response of a spherical atmosphere to thermal and orographic forcing. J. Atmos. Sci., 38, 1179-1196.

Huang, H. P., P. D. Sardeshmukh, and K. M. Weickmann, 1999: The balance of global angular momentum in a long-term atmospheric data set. J. Geophys. Res., 104, 2031-2040.

James, I. N., and P. M. James, 1992: Spatial structure of ultra-lowfrequency variability of the flow in a simple atmospheric circulation model. Quart. J. Roy. Meteor. Soc., 118, 1211-1233.

Joseph, R., M. Ting, and P. J. Kushner, 2004: The global stationary wave response to climate change in a coupled GCM. $J$. Climate, 17, 540-556.

Kushner, P. J., I. M. Held, and T. L. Delworth, 2001: Southern 
Hemisphere atmospheric circulation response to global warming. J. Climate, 14, 2238-2249.

L'Heureux, M. L., and D. W. J. Thompson, 2006: Observed relationships between the El Niño-Southern Oscillation and the extratropical zonal-mean circulation. J. Climate, 19, 276-287.

Limpasuvan, V., and D. L. Hartmann, 2000: Wave-maintained annular modes of climate variability. J. Climate, 13, 4414-4429.

Lorenz, D. J., and D. L. Hartmann, 2001: Eddy-zonal flow feedback in the Southern Hemisphere. J. Atmos. Sci., 58, 33123327.

— , and — 2003: Eddy-zonal flow feedback in the Northern Hemisphere winter. J. Climate, 16, 1212-1227.

—, and E. DeWeaver, 2007: The tropopause height and the zonal wind response to global warming in the IPCC scenario integrations. J. Geophys. Res., 112, D10119, doi:10.1029/ $2006 J D 008087$.

Lu, J., G. A. Vecchi, and T. Reichler, 2007: Expansion of the Hadley cell under global warming. Geophys. Res. Lett., 34, L06805, doi:10.1029/2006GL028443.

- G. Chen, and D. Frierson, 2008: Response of the zonal mean atmospheric circulation to El Niño versus global warming. $J$. Climate, 21, 5835-5851.

Miller, R. L., G. A. Schmidt, and D. T. Shindell, 2006: Forced annular variations in the 20th century Intergovernmental Panel on Climate Change Fourth Assessment Report models. J. Geophys. Res., 111, D18101, doi:10.1029/2005JD006323.

Orlanski, I., 2003: Bifurcation in eddy life cycles: Implications for storm track variability. J. Atmos. Sci., 60, 993-1023.

- 2005: A new look at the Pacific storm track variability: Sensitivity to tropical SSTs and to upstream seeding. J. Atmos. Sci., 62, 1367-1390.

Randel, W. J., and I. M. Held, 1991: Phase speed spectra of transient eddy fluxes and critical layer absorption. J. Atmos. Sci., 48, 688-697.
Robinson, W. A., 1991: The dynamics of the zonal index in a simple model of the atmosphere. Tellus, 43A, 295-305.

— , 2002: On the midlatitude thermal response to tropical warmth. Geophys. Res. Lett., 29, 1190, doi:10.1029/ 2001 GL014158.

Seager, R., N. Harnik, Y. Kushnir, W. Robinson, and J. Miller, 2003: Mechanisms of hemispherically symmetric climate variability. J. Climate, 16, 2960-2978.

Shindell, D. T., and G. A. Schmidt, 2004: Southern Hemisphere climate response to ozone changes and greenhouse gas increases. Geophys. Res. Lett., 31, L18209, doi:10.1029/ 2004GL020724.

Son, S. W., and S. Lee, 2005: The response of westerly jets to thermal driving in a primitive equation model. J. Atmos. Sci., 62, 3741-3757.

Thompson, D. W. J., and J. M. Wallace, 2000: Annular modes in the extratropical circulation. Part I: Month-to-month variability. J. Climate, 13, 1000-1016.

- , and S. Solomon, 2002: Interpretation of recent Southern Hemisphere climate change. Science, 296, 895-899.

- J. M. Wallace, and G. C. Hegerl, 2000: Annular modes in the extratropical circulation. Part II: Trends. J. Climate, 13, 10181036.

Uppala, S. M., and Coauthors, 2005: The ERA-40 re-analysis. Quart. J. Roy. Meteor. Soc., 131, 2961-3012.

Williams, G. P., 2006: Circulation sensitivity to tropopause height. J. Atmos. Sci., 63, 1954-1961.

Yin, J. H., 2005: A consistent poleward shift of the storm tracks in simulations of 21st century climate. Geophys. Res. Lett., 32, L18701, doi:10.1029/2005GL023684.

Yu, J.-Y., and D. L. Hartmann, 1993: Zonal flow vacillation and eddy forcing in a simple GCM of the atmosphere. J. Atmos. Sci., 50, 3244-3259. 